\title{
Dietary protein energy supplementation of pregnant Asian mothers at Sorrento, Birmingham. I: Unselective during second and third trimesters
}

\author{
O A C VIEGAS, P H SCOTT, T J COLE, H N MANSFIELD, PAMELA WHARTON, B A WHARTON
}

\begin{abstract}
At Sorrento Maternity Hospital Asian mothers whose babies had grown poorly in utero had anthropometric and biochemical evidence suggesting an inadequate nutritional state. To test this hypothesis further the effect of unselective dietary protein energy supplementation was studied. A total of 153 Asian mothers received one of three supplements from the 18th to 38th weeks of pregnancy: (a) vitamins only-vitamin C $30 \mathrm{mg}$ daily, iron $3 \mathrm{mg}$ daily; (b) energy-42-80 MJ; (10 000-19 $000 \mathrm{kcal})$ / trimester, all from carbohydrate, plus vitamins; (c) protein energy-energy and vitamins as before, but with $5-11 \%$ of energy from milk protein. By the 28th week mothers receiving the protein energy supplement had put on more weight and more fat than the vitamin-only group. Neither protein energy nor energy supplementation alone enhanced intrauterine growth.

It is concluded that dietary supplementation of all pregnant mothers does not enhance intrauterine growth.
\end{abstract}

\section{Introduction}

Previous work at the Sorrento Maternity Hospital had shown that Asian mothers having poorly grown babies had anthropometric and possibly biochemical evidence of undernutrition. ${ }^{1}$

Sorrento Maternity Hospital, Birmingham B13 9HE

O A C VIEGAS, DA, MRCOG, Mary Crosse research fellow in perinatal medicine

H N MANSFIELD, MD, FRCOG, consultant obstetrician

PAMELA WHARTON, BA, SRD, research dietitian

B A WHARTON, MD, FRCP, consultant paediatrician

Selly Oak Hospital, Birmingham B29

P H SCOTT, BSC, PHD, senior biochemist

MRC Dunn Nutrition Unit, Cambridge CB4 1 XJ

$T$ J COLE, MA, BPHIL, statistician, member of scientific staff
To test this hypothesis further a controlled intervention study of dietary protein energy supplementation was performed. This paper describes a study of unselective supplementation-that is, in which supplements were offered to all Asian mothers irrespective of nutritional state.

\section{Methods}

PLAN OF TRIAL

A total of 153 mothers who booked between 25 April and 29 October 1979 before 20 weeks of gestation, who lived within a defined area of the City of Birmingham (covered by domiciliary midwives' areas 9 and 10, Birmingham Area Health Authority (Teaching)), and who gave informed consent were recruited to the trial. They received one of three supplements throughout the second and third trimesters till the 38th week of pregnancy, beginning in the 18th to 20th weeks (fig 1). Allocation to a particular regimen was designed to give (as

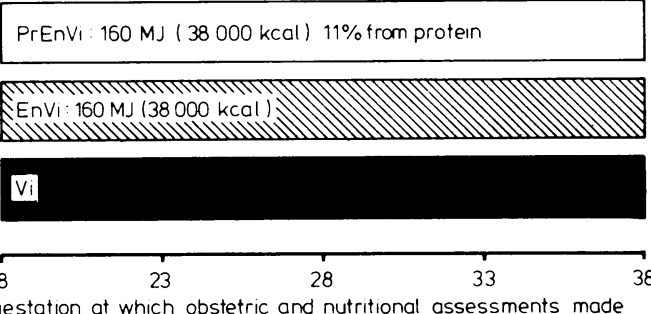

FIG 1 -Plan of supplementation trial. Unselective. (Vi=Vitamins. En $=$ Energy, all from carbohydrate. $\mathrm{Pr}=$ Protein from skimmed milk.)

closely as possible) the same distribution of parity, abnormal past obstetric history, and history of early bleeding in the current pregnancy. Once these factors had been determined in an individual woman a preset plan indicated which supplement she should receive; no discretion was allowed. 


\section{SUPPLEMENTATION REGIMEN}

The vitamin-(Vi)-treated group in effect served as controls; they received half a bottle $(369 \mathrm{ml})$ daily of flavoured carbonated water containing iron $(3 \mathrm{mg})$ and vitamin $C(30 \mathrm{mg})$. The group given energy and vitamins (EnVi) received the same amount of iron and vitamin $\mathrm{C}$ in a flavoured carbonated liquid glucose drink, half a bottle daily, providing $1 \cdot 1 \mathrm{MJ}(273 \mathrm{kcal})$-that is, about $160 \mathrm{MJ}$ (38 000 $\mathrm{kcal}$ ) from 18 to 38 weeks. Women given protein energy and vitamins (PrEnVi) received about the same energy, partly from one-third of a bottle of the liquid glucose drink and the remainder from a chocolateflavoured skimmed-milk powder (26 $\mathrm{g}$ daily), so that $11 \%$ of the total energy intake was from protein. The EnVi and PrEnVi supplements provided the extra dietary allowance of energy and protein during pregnancy currently recommended in Britain-that is, $+1.0 \mathrm{MJ}(+250 \mathrm{kcal})$, with $10 \%$ from protein. ${ }^{2}$

The supplements were delivered to the patients' homes at fiveweek intervals by district midwives or a dietitian, and at the same time the empties from the previous delivery were collected so that apparent consumption could be determined. A dietitian also discussed the use of the supplementation at each five-weekly clinic visit and made at least one other visit to the mothers' homes to check consumption.

\section{PATIENTS}

Most mothers had been born in Pakistan, and many lived in overcrowded conditions and had an abnormal past obstetric history (table I). The groups were broadly similar but the Vi group contained fewer Hindus and more Sikhs and therefore fewer vegetarians; their mean weight and height was greater but none of these differences approached statistical significance.

Assessment-The patients attended the hospital at five-week intervals from 18 weeks of pregnancy for $(a)$ routine obstetric assessment (OACV); (b) anthropometry (OACV); (c) collection of 24-hour urine at weeks 18,23, 33, and 38 for measurement of urinary urea nitrogen (standard Technicon method), total nitrogen, ${ }^{3}$ and sulphate and venepuncture at weeks 28,33 , and 38 for measurement of plasma

TABLE I-Details of mothers studied

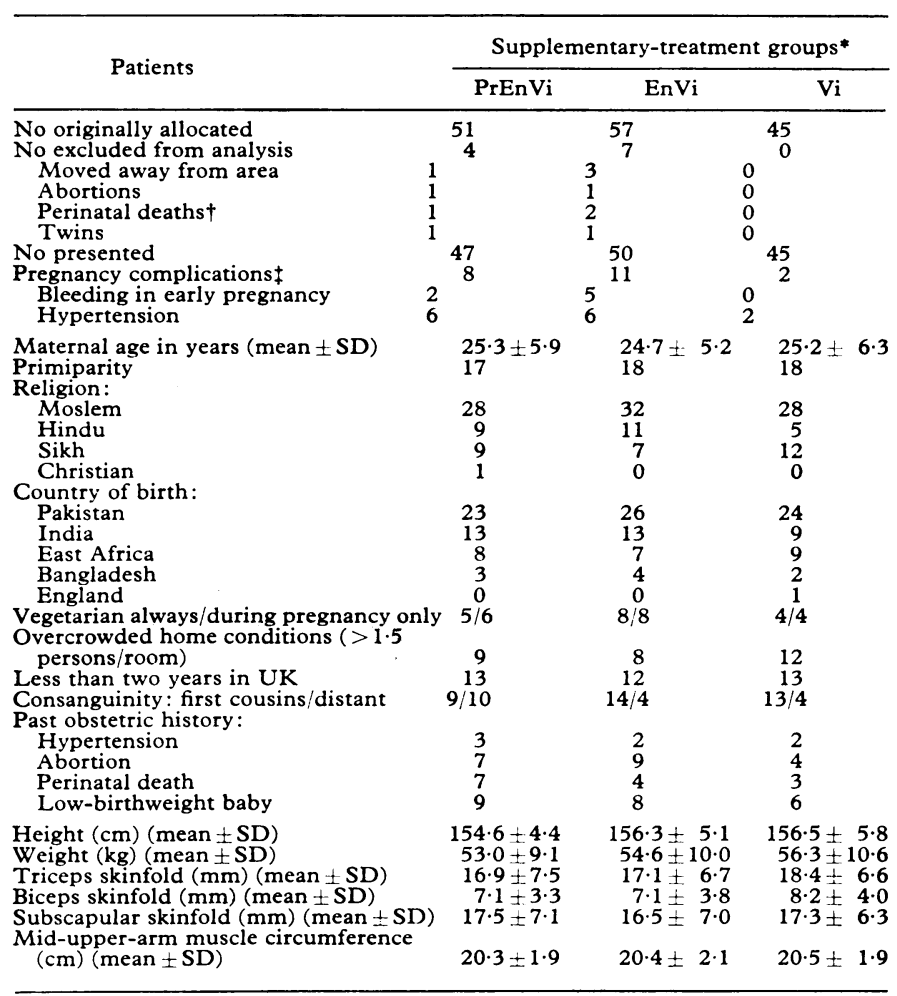

* $\mathrm{Pr}=$ Protein from skimmed milk. En=Energy, all from carbohydrate. Vi=

Vitamins.
tUnexplained intrauterein deaths at 28 and 31 weeks of pregnancy. No specific diagnoses on postmortem examinations. Cause for the one neonatal death large No mragmatic hernia. albumin (manual adaption of the method of Northam and Widdowson $^{5}$ ) and calcium (by cresolphthalein complexone on the Vickers SP120) concentrations and alkaline ribonuclease activity ${ }^{6}$; and $(d)$ dietary assessment (PW)-discussion of the use of the supplements and any problems arising. At birth the babies were weighed by a qualified midwife; other anthropometric estimations were performed within 24 hours of birth by one of two research midwives or a paediatrician.

\section{ANALYSIS OF DATA}

We present weight at birth in three ways: crude birth weight as mean $\pm S D$, and birth weight for gestational age, sex, parity, and maternal height-standard deviation score-using two sets of reference data. The first of these are the well-known Aberdeen data of Thomson et $\mathrm{al}^{7}$; however, since corrections in birth weight for height and parity in Aberdeen mothers arguably do not necessarily apply to Asian mothers we also used a Sorrento internal set of reference data. These are based on a regression analysis of 350 birth weights; highly significant effects were found for gestational age, maternal height, sex, and parity, and these were used to adjust each birth weight to a standard deviation score by subtracting the birth weight predicted from the equation and dividing by the residual standard deviation, $407 \mathrm{~g}$. Differences in crude birth weight and weight standard deviation scores were tested for statistical significance using the two-tailed $t$ test.

We analysed the results, firstly, as a "pragmatic clinical trial" 8 that is, one designed to determine whether a protein energy supplement offered to Asian mothers enhanced intrauterine growth. For this, all Asian mothers entering the trial and producing, at Sorrento, a liveborn singleton baby which survived the neonatal period were included in the analysis. We then reanalysed the results as an "explanatory clinical trial" 8 to examine further the hypothesis that undernutrition led to poor intrauterine growth. The question asked was "Does a protein energy supplement consumed by Asian mothers having otherwise normal pregnancies lead to enhanced intrauterine growth ?" To achieve this, two groups of women were excluded from the analysis. One of these was 19 mothers (seven in the PrEnVi, 10 in the EnVi, and two in the Vi groups) whose pregnancies were complicated by a disorder known to affect intrauterine growth other than poor nutrition-namely, vaginal bleeding or hypertension (diastolic pressure over $90 \mathrm{~mm} \mathrm{Hg}$ on more than one occasion before labour) or both. The other group excluded was 28 mothers (seven in the PrEnVi, 12 in the EnVi, and nine in the Vi groups) who failed to comply with the supplementary regimen. Patients consuming less than $42 \mathrm{MJ}$ (10 $000 \mathrm{kcal}$ ) (or less than $5 \%$ of energy as protein in the PrEnVi group) during each trimester were regarded as not having complied; similar criteria were laid down for mothers in the Vi group, who had to consume a minimum of the vitamin preparation (19 bottles) in each trimester so that there was no risk that this group contained an excess of mothers unwilling to comply with the regimen. Average consumption of supplement was PrEnVi $142 \mathrm{MJ}$ (34000 kcal), $892 \mathrm{~g}$ protein, and EnVi $138 \mathrm{MJ}(33000 \mathrm{kcal})$ throughout pregnancy.

\section{Results}

Maternal anthropometry (fig 2)-When compared with the Vitreated group mothers given PrEnVi put on significantly more weight and fat between the 18 th and 28 th weeks. There were similar trends in the third trimester but none of the differences approached statistical significance.

Maternal biochemistry-There were few differences in biochemical results among the three dietary groups. Compared with the Vitreated group mothers given PrEnVi had higher mean plasma albumin concentrations at week $28(35.8 \pm \mathrm{SD} 1.9 \mathrm{~g} / \mathrm{l} v 34.5 \pm 2.3 \mathrm{~g} / \mathrm{l} ; \mathrm{p}<0.01)$ and a lower mean plasma ribonuclease activity at 33 weeks (385 $\pm \mathrm{SD} 73 \mu \mathrm{mol} / 1 v 433 \pm 85 \mu \mathrm{mol} / \mathrm{l} ; \mathrm{p}<0.02$ ). Table A (available on request) shows all the other biochemical results.

Size of baby at birth (fig 3)-The birth weights, weight centiles, and placental weights were similar in the three treatment groups. Other measurements of the babies were broadly similar, although babies of PrEnVi-treated mothers had a greater triceps skinfold thickness $(p \approx 0.06)$ and a shorter mid-upper-arm muscle circumference $(p<0.02)$ than had babies in the Vi-treatment group. (Table B (available on request) gives all the numerical details summarised in fig 3 together with detailed anthropometric data of the babies in the 


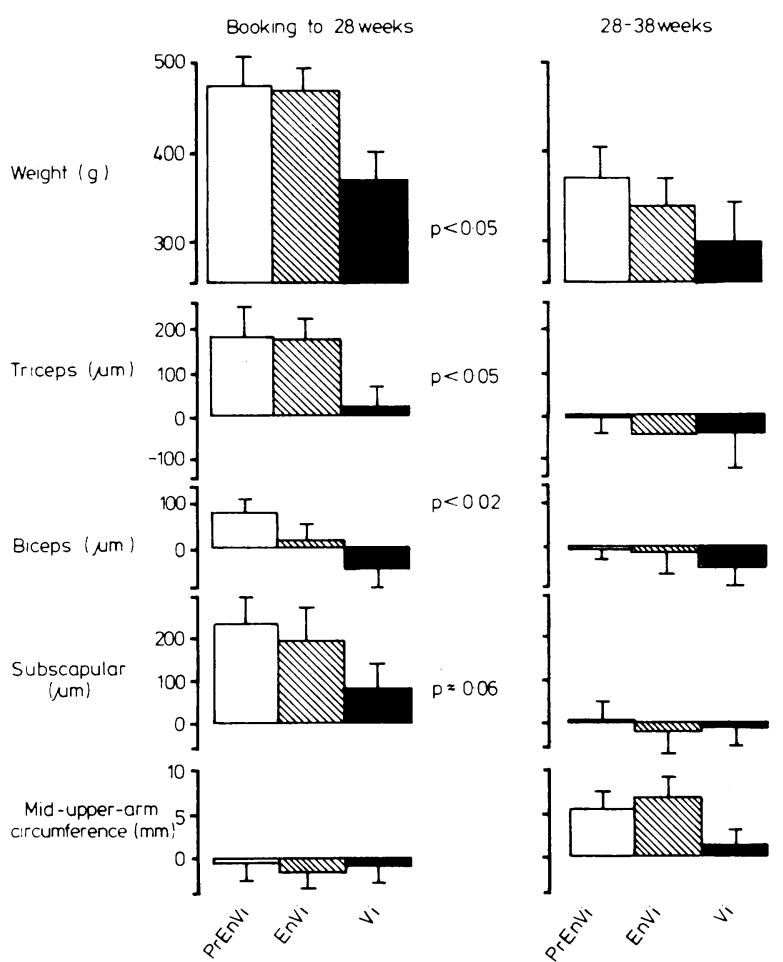

FIG 2-Mean anthropometric increments/week ( $\pm \mathrm{SE}$ ) in mothers given supplements from 18 weeks. Values of $p$ indicate significance of difference between PrEnVi and Vi groups (key to groups as in fig 1). Values of $p$ greater than 0.09 not shown.

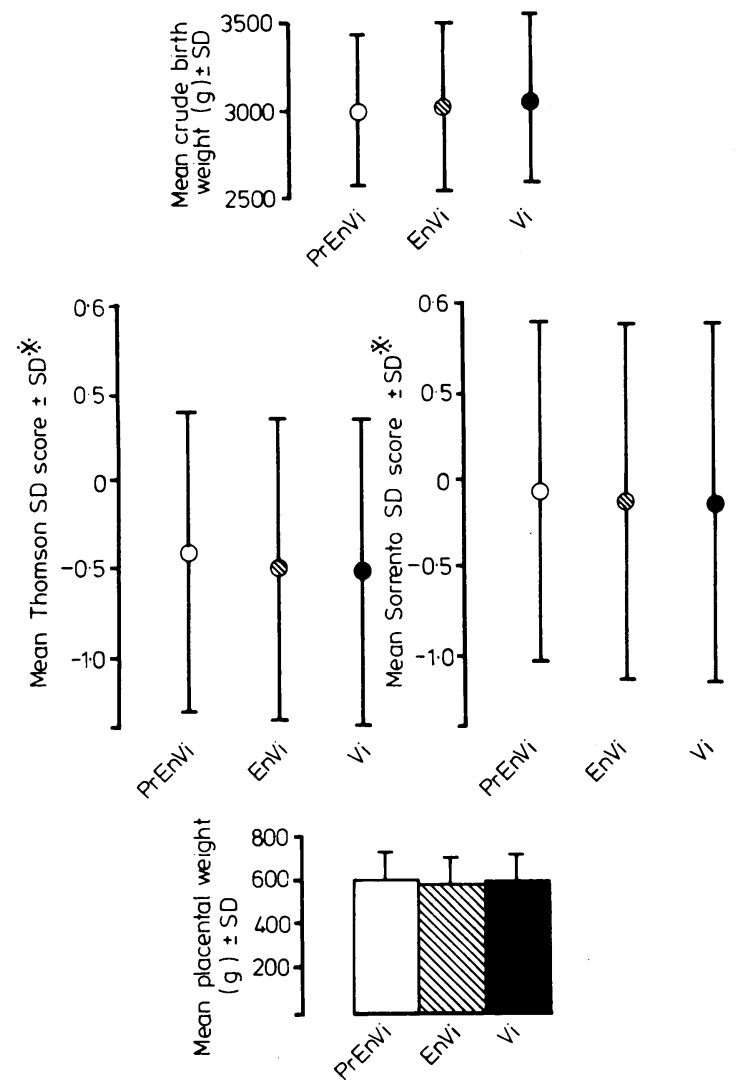

FIG 3-Birth weight, birthweight centile,* and placental weight in mothers given supplement from 18 weeks of pregnancy.

* Birthweight centile for gestational age, sex, parity, and maternal height according to data of Thomson et $a l^{7}$ and internal Sorrento data (see Methods). (Key to groups as in fig 1.) three groups.) When the results were analysed as an "explanatory clinical trial"- - that is, with the omission of pathological pregnancies and poor compliers-there were again no significant differences in birth weight, weight centiles, and placental weights (table $\mathrm{C}$ (available on request) shows this analysis).

\section{Discussion}

Protein energy supplementation of all Asian mothers did not increase the average size of their babies. This result was similar to that in Harlem, New York, where only a small effect of nutritional supplementation on birth weight $(+41 \mathrm{~g}$; not significant) was observed. ${ }^{9}$

The following seven factors might explain why a protein energy supplement failed to enhance intrauterine growth.

Imperfect matching of groups-Women in the Vi-treatment group were taller and heavier and so would tend to have had heavier babies. This was allowed for to some extent by the use of weight centiles, which correct for maternal height. The mean weight centiles in the PrEnVi group were higher but the differences were far from statistically significant.

Groups too small-The size of the PrEnVi and Vi groups would have allowed a difference of $150 \mathrm{~g}$ to be significant at the $5 \%$ level. It may be argued that any smaller difference would have little clinical relevance.

Failure to comply-Although some method of marking the supplements would have been useful we are reasonably confident of compliance, not only because of the checking system used but also because the greater increase in weight and fat was observed within the groups given supplements. When noncompliers were excluded the results remained similar.

Supplements replaced normal diet-Dietary surveys (to be published elsewhere) suggested that rarely supplements replaced the normal diet. Nevertheless, the greater weight gain of women given PrEnVi and EnVi suggests that the supplements were taken mostly in addition to the normal diet.

Supplements were of inadequate size-Supplements may have been inadequate. Nevertheless, the mean supplementary intakes among women who complied were PrEnVi $142 \mathrm{MJ}$ and EnVi $138 \mathrm{MJ}$, which were well above the "threshold" of $84 \mathrm{MJ}$ $(20000 \mathrm{kcal})$ for an effect on birth weight seen in Guatemalan studies of nutrition in pregnancy. ${ }^{10}$

Undernutrition not major cause of reduced intrauterine growthThe reduced intrauterine growth seen in developing countries has been ascribed to undernutrition, ${ }^{11}$ but other environmental factors-for example, the mothers' work during pregnancymay be more important. ${ }^{12}$

Mothers were unselected - "Treatment" of a whole population may have been inappropriate: only mothers nutritionally at risk of having a poorly grown baby should have been given supplements. We examine this in our accompanying paper.

We conclude that the mothers given supplements did achieve weight gain regarded as optimal in current obstetric practice. This may have been an advantage for them, although there was no evidence of it in our study.

We are grateful to Mr P G Needham, consultant obstetrician, for allowing us to study patients under his care; Mr P Scott, head of the biochemistry department, Selly Oak Hospital; Mrs J King and Mrs $\mathrm{T}$ Bansal, research midwives; Miss $\mathrm{K}$ Snow, medical illustrations department, Birmingham Children's Hospital; the community midwives of areas 9 and 10; Mrs P Cox for secretarial help; and Beecham Research Laboratories, who provided the nutritional supplements.

Tables A, B, and C may be obtained from Dr B A Wharton.

\section{References}

${ }^{1}$ Bissenden JG, Scott PH, King J, Hallum J, Mansfield HN, Wharton BA. Anthropometric and biochemical changes during pregnancy in Asian and European mothers having light for gestational age babies. $\mathrm{Br} \mathfrak{F}$ Obstet Gynaecol 1981 ;88:999-1008. 
${ }^{2}$ Department of Health and Social Security. Recommended daily amounts of food energy and nutrients for groups of people in the United Kingdom. Reports on health and social subjects. No 15. London: HMSO, 1979.

4 Shahinian AH, Reinhold JG. Application of the phenol-hypochlorite reaction to measurement of ammonia concentrations in Kjeldhal digests of serum and various tissues. Clin Chem 1971;17:1077-80.

4 Yatzidis H, Oreopoulous D, Symvoulidis A, Triantaphyllidis D, Yannitsiotis A. Une methode simple pour le dosage des sulfates dans les serum et l'urine. Revue Française d'Études Cliniques et Biologiques $1964 ; 9: 126-33$.

${ }^{5}$ Northam BE, Widdowson GF. The determination of serum albumin by autoanalyser using bromocresol green. Association of Clinical Biochemists' Technical Bulletin 1967; No 11 .

${ }^{6}$ Scott PH, Berger HM, Kenward C, Scott P, Wharton BA. Plasma alkaline ribonuclease (EC 1.4.22) and nitrogen retention in low-birthweight infants. Br $\mathcal{F}$ Nutr 1978;40:459-64.
7 Thomson AM, Billewicz WZ, Hytten FE. The assessment of fetal growth. Fournal of Obstetrics and Gynaecology of the British Commonwealth 1968;75:903-16.

* Gore S. Assessing clinical trials-trial discipline. Br Med f 1981 ;283 211-3.

${ }^{9}$ Rush D, Stein Z, Susser M. A randomized controlled trial of prenatal nutritional supplementation in New York City. Pediatrics 1980;65: 685-97.

${ }^{10}$ Lechtig A, Habicht JP, Delgado H, Klein RE, Yarbrough C, Martorell R. Effect of food supplementation during pregnancy on birthweight. Pediatrics $1975 ; 56: 508-19$.

11 Lechtig A, Delgado H, Lasky R, et al. Maternal nutrition and fetal growth in developing countries. Am $\mathcal{F}$ Dis Child 1975;129:553-6.

12. Briend A. Fetal malnutrition-the price of upright posture. $\mathrm{Br}$ Med $\mathcal{F}$ 1979 ;ii:317-9.

(Accepted 4 fune 1982)

\section{Dietary protein energy supplementation of pregnant Asian mothers at Sorrento, Birmingham. II: Selective during third trimester only}

O A C VIEGAS, P H SCOTt, T J COLE, PHyllis EATON, P G NEEDHAM, B A WhARTON

\begin{abstract}
Unselective dietary protein energy supplementation of Asian mothers at Sorrento Maternity Hospital did not enhance intrauterine growth. The effect of selective supplementation was therefore studied. Forty-five mothers who at 28 weeks were known to be nutritionally at risk (triceps increment $\leqslant 20 \mu \mathrm{m} /$ week between 18 and 28 weeks) received one of three supplements during the third trimester: (a) vitamins only-a multivitamin sachet daily containing vitamins $A, B, C$, and $D$; (b) energy42-125 MJ (10 000-30 $000 \mathrm{kcal})$, all from carbohydrate, plus vitamins; (c) protein energy-energy and vitamins as before, but with $5-10 \%$ of energy from milk protein. Eighty-three mothers regarded as adequately nourished at 28 weeks also received one of the three supplements. In the nutritionally at-risk mothers the protein energy supplement was associated with a heavier crude birth weight and heavier weight for gestational age. Supplementation did not lead to improved intrauterine growth in those mothers who were adequately nourished.

The differential effect of supplementation depending on the mothers' nutritional state during the second trimester may explain apparently conflicting results of other studies where some have shown a substantial effect of supplementation and others only a small effect. This effect of intervention is further evidence that "poor
\end{abstract}

Sorrento Maternity Hospital, Birmingham B13 9HE

O A C VIEGAS, DA, MRCOG, Mary Crosse research fellow in perinatal medicine

PHYLLIS EATON, BSC(NUT), SRD, research dietitian

P G NEEDHAM, FRCS, MRCOG, consultant obstetrician

B A WHARTON, MD, FRCP, consultant paediatrician

Selly Oak Hospital, Birmingham B29

P H SCOTT, BSC, PHD, senior biochemist

MRC Dunn Nutrition Unit, Cambridge CB4 1XJ

T J COLE, MA, BPHIL, statistician, member of scientific staff nutrition" contributes to poor intrauterine growth in selected mothers, even in developed countries.

\section{Introduction}

Unselective dietary protein energy supplementation of all Asian mothers at Sorrento Maternity Hospital irrespective of nutritional state during the second and third trimesters of pregnancy did not enhance intrauterine growth. ${ }^{1}$ This study examines the effect of selective supplementation-that is, in which dietary supplements were given to mothers during the third trimester if anthropometric evidence of undernutrition had been detected in the second trimester. It also describes the effect of giving supplements to mothers who had no preceding evidence of undernutrition.

\section{Methods}

PLAN OF TRIAL

We recruited to the trial 130 women who booked between 5 November 1979 and 11 June 1980 before 20 weeks of gestation, who lived within a defined area of the City of Birmingham (covered by domiciliary midwives' areas 9 and 10, Birmingham Area Health Authority (Teaching)), and who gave informed consent. They entered the trial at 18 to 20 weeks but received only iron ( $3 \mathrm{mg}$ daily) and vitamin $\mathrm{C}$ ( $30 \mathrm{mg}$ daily) until 28 weeks (fig 1 ). The mothers were then divided into $(a)$ those who from evidence of other work at this hospital ${ }^{2}$ were nutritionally at risk of having a light for gestational age baby as shown by an inadequate increase in triceps skinfold thickness increment $(\leqslant 20 \mu \mathrm{m} /$ week during the second trimester $\mathrm{n}=45$ ), and $(b)$ those with an adequate increase in triceps skinfold thickness increment ( $>20 \mu \mathrm{m} /$ week) during the second trimester; these are referred to as adequately nourished $(n=85)$.

\section{SUPPLEMENTATION REGIMEN}

Members of each group were then assigned at random to one of three supplement groups: $\mathrm{Vi}$, a multivitamin sachet (Orovite 7 ); EnVi, a multivitamin sachet plus glucose syrup (Hycal) providing 